\title{
MASTER
}

\section{STOP BANDWIDTHS OF NONLINEAR BEAM-BEAM RESONANCES}

G. Parzen

December 8, 1979

BROOKHAVEN NATIONAL LABORATORY ASSOCIATED UNIVERSITIES, INC. UNDER CONTRACT NO. DE-ACO2-76CH00016 WITH THE UNITED STATES DEPARTMENT OF ENERGY 


\section{DISCLAIMER}

This report was prepared as an account of work sponsored by an agency of the United States Government. Neither the United States Government nor any agency Thereof, nor any of their employees, makes any warranty, express or implied, or assumes any legal liability or responsibility for the accuracy, completeness, or usefulness of any information, apparatus, product, or process disclosed, or represents that its use would not infringe privately owned rights. Reference herein to any specific commercial product, process, or service by trade name, trademark, manufacturer, or otherwise does not necessarily constitute or imply its endorsement, recommendation, or favoring by the United States Government or any agency thereof. The views and opinions of authors expressed herein do not necessarily state or reflect those of the United States Government or any agency thereof. 


\section{DISCLAIMER}

Portions of this document may be illegible in electronic image products. Images are produced from the best available original document. 


\section{STOP BANDWIDTHS OF NONLINEAR BEAM-BEAM RESONANCES}

G. Parzen

December 8, 1979

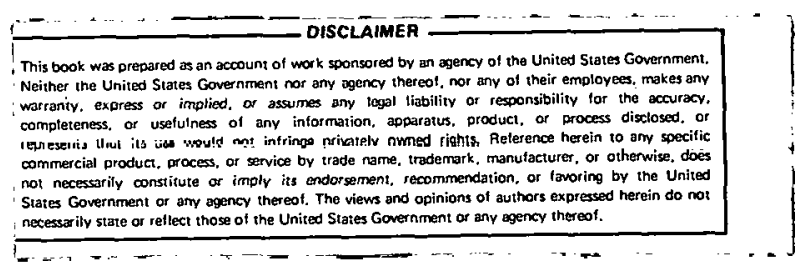

1

\section{ACCELERATOR DEPARTMENT}

BROOKHAVEN NATIONAL LABORATORY UPTON, NEW YORK 11973 


\section{DISCLAIMER}

This book was prepared as an account of work sponsored by an agency of the United

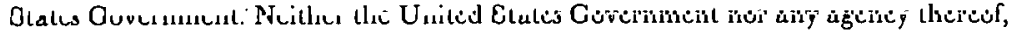
nor any of their employees, makes any warranty, express or implied, or assumes any legal liability or responsibility for the accuracy, completeness, or usefulness of any information, apparatus, product, or process disclosed, or represents that its use would not infringe privately owned rights. Referenoe herein to any specific commercial prod. uct, process, or service by trade name, trademark, manufacturer, or otherwise, does not necessarily constitute or imply its endorsement, recommendation, or favoring by the United States Government or any agency thereof. The views and opinions of authors expressed herein do not necessarily state or reflect those of the United States Government or any agency thereof.

Printed in the United States of America Available from

National Technical Information Service

U.S. Department of Commerce

5285 Port Royal Road

Springfield, VA 22161

Price: Printed Copy 
A general expression is given for the stop bandwidths, $\Delta \nu$, of nonlinear beam-beam resonances, which is expanded in powers of $\mathrm{N}^{\prime}(\mathrm{s})$, the vertical beam orbit, and which is valid under certain assumptions regarding the orbits and charge distributions near the interaction regions. This result is applied to obtain results for the rms $\Delta v$ due to random vertical orbit errors, and due to random errors in $\mathrm{N}_{\beta}$ at the crossing points. Numerical results are given for the ISABELLE storage accelerator. 


\section{INTRODUCTION}

Results are derived for stop bandwidths, $\Delta v_{\mathrm{N}}$, of nonlinear resonances due to the beam-beam interaction of horizontally crossing beams. A general result is first given for $\Delta v_{N}$, which involves only the charge distributions $\rho(x, y)$ and not the fields themselves, which is based on the assumptions that $\beta_{y}(s)$ can be regarded as constant in the interaction region, and that the beam paths near the crossing points may be curved vertically but are straight lines crossing at an angle $\alpha$ horizontally. Assuming that the charge distribution is Gaussian vertically, the result is expanded in powers of $\mathrm{y}(\mathrm{s})$, the vertical orbit near the crossing points.

These general results are applied to obtain results for the, rms $\Delta v_{N}$, due to random vertical orbit errors, and due random errors in $\beta_{y}$ at the crossing points. Numerical results are given for the ISABELLE storage accelerator.

II. THEORY and GENERAL RESULTS

The half-width of the stop band of the nonlinear resonance $N v_{y}=q$ is given by the often derived formula $1-3$

$$
\Delta \nu_{N}=\frac{F(N)}{2^{N-2}} \frac{1+B^{2}}{B} \frac{1}{4 \pi} \int d s \frac{B}{B \rho}(\sqrt{B \varepsilon})^{N-2} \frac{1}{(N-1) !} D_{y}^{N-1} E_{y} \exp (i N \phi),
$$

where $E$ is the field acting on the test beam due to the other bean and $D_{y}^{n} \underline{\underline{Y}} \partial^{n} / \partial y^{n}$. The factor $F(N)$ is often onitted and is given by

$$
\begin{array}{rlrl}
F(N) & =1 & , N=2 \\
& =0.9 & , N=3 \\
& =0.5 \quad, N=4 \\
& =\pi^{(N-2) / 2}, N \geq 5
\end{array}
$$

1. E. Keil, CERN Report CERN/ISR-TH/72-25 (1972)

2. P.M. Hanney \& E. Keil, CERN Report CERN/ISR-TH/73-55 (1973)

3. G. Guignard, CERN Report CERN 78-11 (1978) 
It is assumed in this note that the factors $\beta_{y}$ and $\exp$ (in $\emptyset$ ) do not vary rapidly and can be treated as constant and evaluated at the crossing point of the two beams. It can be shown ${ }^{4}$ that under certain conditions

$$
\int d s D_{y}^{n-1} E_{y}=4 \pi \int d s D_{y}^{n-2} \rho,
$$

where $\rho(x, y)$ is the charge density distribution of the beam creating the field $E_{y}$. The required conditions are that the position of the test beam relative to the other be given by

$$
\begin{aligned}
& \ddot{x}=\alpha \dot{s}, \\
& y=y(s),
\end{aligned}
$$

where the beams are crossing in the horizontal plane and $\alpha$ is the angle between them which is assumed to be sma11. The result, Eq.(2.3) follows from the invariance of the interaction integrals when the test beam is displaced by an amount $\Delta s$ in the longitudinal direction of the other beam. Equation (2.4) says that the test beam moves along a straight line horizontally, but its path can be curved vertically.

It will be assumed that $p(x, y)$ is Gaussian in the vertial direction and is given by

$$
\rho(x, y)=\rho_{1}(x) \exp \left(-y^{2} / 2 \sigma_{y}^{2}\right) /\left(2 \pi \sigma_{y}\right)^{\frac{1}{2}}
$$

One thus finds for $\Delta \nu_{N}$

$$
\begin{aligned}
& \Delta \nu_{N}=\Delta \nu \cdot \frac{f(N) e^{i N \phi}}{2(N-2) / 2(N-1) !} \alpha \int d s \rho_{1}(x) D_{\mu}^{N-2} e^{-\mu^{2}} \\
& \mu^{2}=y^{2} / 2 \sigma_{y}, \\
& \Delta \nu=\frac{1+B^{2}}{B} \frac{B}{B \rho} \frac{I}{v} \frac{1}{(2 \pi)^{\frac{1}{2}} \sigma_{y} \alpha} \\
& f(N)=1, \quad N=2 \\
& f(N)=0.9 \pi^{\frac{1}{2}}, \quad N=3 \\
& f(N)=0.5 \pi, \quad N=4 \\
& f(N)=1, \quad N . \quad N=5,
\end{aligned}
$$

4. M. Cornacchia \& G. Parzen, Forthcoming BNL Report (1979) 
and $(\beta \in / \pi)^{\frac{1}{2}}=2 \sigma$ was used. $\Delta \nu$ is the linear beam-beam $\nu$-shift. We will now Expand the integrand in powers of $y$, and keep just the lowest terms. One can show that for $n$ odd

$$
\begin{aligned}
D_{y}^{n} e^{-y^{2}}= & e^{-y^{2}}\left[(2 y)^{n}-\frac{n(n-1)}{1 !}(2 y)^{n-2}\right. \\
& +\frac{n(n-1)(n-2)(n-3)}{2 !}(2 y)^{n-4} \cdots \\
& \left.-\frac{n !}{((n-1) / 2) !} 2 y\right]
\end{aligned}
$$

and for $\mathrm{n}$ even

$$
\begin{aligned}
D_{y}^{n} e^{-y^{2}=e^{-y^{2}}} & {\left[(2 y)^{n}-\frac{n(n-1)}{1 !}(2 y)^{n-2}\right.} \\
& +\frac{n(n-1)(n-2)(n-3)}{2 !}(2 y)^{n-4} \cdots \\
& \left.-\frac{n ! / 2}{(n / 2-1) !}(2 \dot{y})^{2}+\frac{n !}{(n / 2) !}\right]
\end{aligned}
$$

Keeping just the lowest powers in $\mathrm{y}$ we find for odd $\mathrm{N}$

$$
\begin{aligned}
& \Delta \nu_{N}=\Delta \nu \frac{f(N)}{2(N-1) / 2} \frac{1}{((N-1) / 2) !} A, \\
& A=\alpha \int \mathrm{ds} \rho_{1}(\mathrm{x}) \mathrm{y} / \sigma_{\mathrm{y}} \cdot \exp (\text { in } \emptyset) .
\end{aligned}
$$

For even $N$

$$
\begin{aligned}
& \Delta \nu_{N}=\Delta \nu \frac{f(N)}{2^{(N-2) / 2}} \frac{1}{[(N-2) / 2] !} \frac{1}{N-1} \cdot A, \\
& A=\alpha \int d s \rho_{1}(x)\left[1-(N-1) \frac{y^{2}}{2 \sigma_{y}^{2}}\right] \exp (i n \emptyset) \text {. }
\end{aligned}
$$

$\emptyset$ is the phase, $\nu \emptyset=\int \mathrm{d} s\left(1 / \beta_{\mathrm{y}}\right)$

If $y(s)=0$ at the crossing points, then Eq. (2.8) gives nonzero results only for the even resonances, which is the case in the absence of vertical orbit errors. 
III. $\Delta \nu_{\mathrm{n}}$ DUE TO VERTICAL ORBIT ERRORS AT THE CROSSING POINTS

Vertical orbit errors at the crossing points make the beam-beam interactions different at the crossing points and generate resonances which lie close to the working line in $\nu_{x}, \nu_{y}$ space. The results given by Eq. $(2.8)$ have to sumed over all the crossing points. In computing the integral over $s, y(s)$ may be considered as constant and evaluated at the crossing points.

For $\mathrm{N}$ odd, the rms value of the stop band half-width is given by:

$$
\Delta \nu_{N}, \mathrm{rms}=\Delta \nu \frac{f(N)}{2^{(N-1) / 2}[(N-1) / 2] !} \cdot \mathrm{N}_{\mathrm{cp}}^{\frac{1}{2}} y_{\mathrm{rms} / 2 \sigma_{\mathrm{y}}}
$$

where $\mathrm{N}_{\mathrm{CP}}$ is the number crosining points and $\mathrm{y}_{\mathrm{rms}}$ is the rms value of the verfical orbit error at the crossing pointes.

For $\mathrm{N}$ even, $\Delta \nu_{\mathrm{N}}$ is proportional to $\mathrm{y}^{2}$. The quantity $\mathrm{A}$ in

Eq. (2.8) becomes

$$
A=(N-1) \sum_{k} e^{i N \emptyset_{k}} y_{k^{\prime}}^{2} / 2 \sigma_{y}^{2},
$$

where the sum over $\mathrm{k}$ is over all the crossing points.

For the moment it will be assumed that $\mathrm{N}$ is not a multiple of $\mathrm{N}_{\mathrm{cp}}$ and $\Sigma_{k} \exp \left(i N \emptyset_{k}\right)=0$. Then one can write

$$
A=(N-1) \Sigma_{k} e^{i N \emptyset_{k}}\left(y_{k}^{2}-\left\langle y^{2}\right\rangle\right) / 2 \sigma_{y}^{2}
$$

where $\left\langle y^{2}\right\rangle$ is the average value of $y_{k}^{2}$, and the average value of $A^{2}$ is given by

$$
\left\langle A^{2}\right\rangle=\frac{(N-1)^{2}}{4 \sigma_{y}^{4}} \sum_{k k}\left\langle e^{i n\left(\phi_{k}-\phi_{k}\right)}\left[y_{k}^{2}-\left\langle y^{2}\right\rangle\right]\left[y_{k}{ }^{2}-\left\langle y^{2}\right\rangle\right]\right\rangle
$$

$$
\begin{aligned}
& \text { Since }\left[y_{k}^{2}-\left\langle y^{2}\right\rangle\right] \text { and }\left[y_{k}{ }^{2}-\left\langle y^{2}\right\rangle\right] \text { are } \\
& \qquad \begin{aligned}
\left\langle A^{2}\right\rangle & =\frac{(N-1)^{2}}{4 \sigma_{y}^{4}} \sum_{k}\left\langle\left[y_{k}^{2}-\left\langle y^{2}\right\rangle\right]^{2}\right\rangle \\
& \cdots \frac{(N-1)^{2}}{4 \sigma_{y}^{4}} \cdot N_{c p}\left[\left\langle y^{4}\right\rangle-\left\langle y^{2}\right\rangle^{2}\right],
\end{aligned}
\end{aligned}
$$


and

$$
A_{\text {rms }}=(N-1) \cdot N_{c p}^{\frac{1}{2}}\left[\left\langle y^{4}\right\rangle-\left\langle y^{2}\right\rangle^{2}\right]^{\frac{1}{2}} / 2 \sigma_{y}^{2}
$$

Now $\left\langle\mathrm{y}^{2}\right\rangle=\mathrm{y}_{\mathrm{rms}}^{2}$ and for a Gaussian distribution $\left\langle\mathrm{y}^{4}\right\rangle=3 \mathrm{y}_{\mathrm{rms}}^{2}$. Thus,

$$
\mathrm{A}_{\mathrm{rms}}=(\mathrm{N}-1) \mathrm{N}_{\mathrm{cp}}^{\frac{3}{2}} \cdot 1.41 \mathrm{y}_{\mathrm{rms}}^{2} \cdot
$$

For $N$ even, and $N$ not a multiple of $N_{c p}$, the rms value of $\Delta \nu_{N}$ is given by

$$
\Delta v_{\mathrm{N}, \mathrm{rms}}=\Delta v \frac{\mathrm{f}(\mathrm{N})}{2^{(\mathrm{N}-2) / 2}} \frac{1.41}{[(\mathrm{~N}-2) / 2] !} \mathrm{N}_{\mathrm{cp}}^{\frac{1}{2}} \mathrm{y}_{\mathrm{rms}}^{2} / 2 \sigma_{\mathrm{y}}^{2}
$$

If $\mathrm{N}$ is even, and $\mathrm{N}$ is a multiple of $\mathrm{N}_{c p}$, then $\Sigma_{k} \exp \left(i N \emptyset_{k}\right)=\mathrm{N}_{c p}$,
$\Delta \nu$ has a nonzero average value. and $\Delta \nu_{N}$ has a nonzero average value.

$$
\left\langle\Delta \dot{\nu}_{\mathrm{N}}\right\rangle=\Delta \nu \frac{\mathrm{f}(\mathrm{N})}{2^{(\mathrm{N}-2) / 2}} \cdot \mathrm{N}_{\mathrm{cp}} \mathrm{y}_{\mathrm{rms}}^{2} / 2 \sigma_{\mathrm{y}}^{2},
$$

And around this average value, $\Delta v$ has a statistical fluctuation whose rms value $\left[\Delta v_{N}-\left\langle\Delta v_{N}\right\rangle \mathrm{rms}_{\mathrm{N}}\right.$, is given by Eq. (3.2).

For this case, one can introduce a pseudo $\Delta v_{N}$, rms defined by the requirement that $2 \Delta v_{\mathrm{N}}$, rms gives roughly the peak $\Delta v_{\mathrm{N}}$, and the pseudo $\Delta \nu_{N}, r m s$ is given by

$$
\Delta \nu_{N, \mathrm{rms}}=\Delta \nu \frac{\mathrm{f}(\mathrm{N})}{2^{(\mathrm{N}-2) / 2}} \frac{\left(0.5 \mathrm{~N}_{\mathrm{cp}}+1.41 \mathrm{~N}_{\mathrm{cp}}^{\frac{1}{2}}\right)}{[(\mathrm{N}-2) / 2] !} \mathrm{y}_{\mathrm{rms}}^{2} / 2 \sigma_{\mathrm{y}}^{2} \text {, }
$$

where $\mathrm{N}$ is even and a multiple of $\mathrm{N}_{\mathrm{cp}}$.

IV. $\Delta \nu_{\mathrm{N}}$ DUE TO RANDOM ERRORS IN $\beta_{\mathrm{y}}$ AT THF CROSSING POINTS

Random errors in $\beta$ at the crossing point can excite resonances close to the working line. The linear beam-beam $v$-shift, $\Delta v$, will be different at each crossing point. If one assumes that $\sigma_{y}$ is
due entirely to betatron oscillation, then $\Delta \nu \alpha \beta^{\frac{2}{2}}$ and

$$
\frac{\Delta v}{v}=\frac{1}{2} \frac{\Delta \beta_{y}}{\beta_{y}}
$$


On1y even resonance are generated and from Eq. (2.8), the rms value of the stop band width is given by

$$
\Delta \nu_{N, r m s}=\Delta \frac{f(N)}{2(N-2) / 2}\left[\frac{1}{(N-2) / 2] !} \frac{1}{N-1} N_{c p}^{\frac{1}{2}} \frac{1}{2}\left(\frac{\Delta \beta_{y}}{\beta_{y}}\right)\right. \text { rms, }
$$

where $\left(\Delta \beta_{y} / \beta_{y}\right)$ is the rms value of the error in the vertical $\beta$-function at Effe crossing points.

\section{NUMERICAL RESULTS FOR ISABELLE}

The results given in Sections III and IV can be applied to compute the stop-hand half widths, $\Delta v_{N}$ due to raltumin vertical orbit errors, and random errors in $\beta{ }^{N}$ at the crossing points for the ISABELLE storage accelerator:

Results are given below at two energies, $30 \mathrm{GeV}$ and $400 \mathrm{GeV}$. For the even order resonance, the contributions due to random vertical orbit errors, $\Delta v$, and due to random errors in $\beta, \Delta \nu_{N}, \beta$ are given separately $y$ and $\Delta \nu_{N}$ is the rms sum of these two ${ }^{N}$, contributions. For the odd order resonance, $\Delta v_{\text {is }}$ is due to the vertical orbit errors only. It was assumed that the rms error in the vertical orbit at the crossing points is the same as $30 \mathrm{GeV}$ and $400 \mathrm{GeV}$ and is $\mathrm{y}_{\mathrm{ms}}=0.05 \mathrm{~mm}$. It may be possible to correct the orbit betterms at $400 \mathrm{GeV}$ because of the smaller size of the beam.

\section{$\underline{30 \mathrm{GeV}}$}

$$
\begin{aligned}
& \alpha=0.011, I=8 \mathrm{~A}, \beta_{y}=7.5 \mathrm{~m}, \sigma_{y}-0.75 \mathrm{~mm}, y_{\mathrm{rms}}=0.05 \mathrm{~mm}, \\
& \mathrm{~N}_{\mathrm{cp}}=6,\left(\Delta \beta_{\mathrm{y}} / \beta_{y}\right)_{\mathrm{rms}}=0.045, \Delta \nu=0.0058 .
\end{aligned}
$$

\begin{tabular}{|c|c|c|c|c|c|}
\hline $\mathrm{N}$ & $\Delta v_{N}$ & $\mathbf{N}$ & $\Delta v N, B$ & $\Delta v_{N, y}$ & $\Delta v_{N}$ \\
\hline & & 2 & $3.20 \mathrm{E}-4$ & $4.46 E-5$ & $3.23 \mathrm{E}-4$ \\
\hline 3 & $7.55 \mathrm{E}-4$ & 4 & $8.37 E-5$ & 3.47 E-5 & $9.06 \mathrm{E}-5$ \\
\hline 5 & $1.18 \mathrm{E}-4$ & 6 & $7.99 \mathrm{Fi}-6$ & $1.03 \mathrm{E}-5$ & $1.31 \mathrm{E}-5$ \\
\hline 7 & $1.97 \mathrm{E}-\mathrm{b}$ & 8 & $9.51 \mathrm{E}-7$ & $9.21 \mathrm{E}-7$ & 1. $.32 \mathrm{E}-6$ \\
\hline 9 & $2.47 E-6$ & 10 & $9.25 \mathrm{E}-8$ & $1.15 \mathrm{E}-7$ & $1.48 \mathrm{E}-7$ \\
\hline 11 & $2.47 \mathrm{E}-7$ & 12 & $7.57 \mathrm{E}-9$ & $2.15 \mathrm{E}-8$ & $2.28 \mathrm{E}-8$ \\
\hline 13 & $2.05 E-8$ & 14 & $5.33 \mathrm{E}-10$ & $9.57 \mathrm{E}-10$ & $1.09 \mathrm{E}-9$ \\
\hline 15 & $1.46 \mathrm{E}-9$ & 16 & $3.30 \mathrm{E}-11$ & $6.85 \mathrm{E}-11$ & $7.60 \mathrm{E}-11$ \\
\hline 17 & $9.18 \mathrm{E}-11$ & 18 & $1.82 \mathrm{E}-12$ & $8.03 \mathrm{E}-12$ & $8.23 \mathrm{E}-12$ \\
\hline 19 & $5.10 \mathrm{E}-12$ & 20 & $9.05 \quad E-14$ & $2.38 \mathrm{E}-13$ & $2.54 \mathrm{E}-13$ \\
\hline
\end{tabular}




\section{$400 \mathrm{GeV}$}

$$
\begin{aligned}
& \alpha=0.011, I=8 \mathrm{~A}, \beta_{y}=7.5 \mathrm{~m}, \sigma_{y}=0.21 \mathrm{~mm}, y_{r m s}=0.05 \mathrm{~mm}, \\
& N_{c p}=6,\left(\Delta \beta_{y} / \beta_{y}\right)_{r m s}=0.045, \Delta \nu=0.00156 .
\end{aligned}
$$

\begin{tabular}{rrrllll}
\multicolumn{1}{r}{$N$} & \multicolumn{1}{c}{$\Delta \nu_{\mathrm{N}}$} & \multicolumn{1}{c}{$\Delta \nu_{\mathrm{N}, \beta}$} & \multicolumn{1}{c}{$\Delta \nu_{\mathrm{N}, \mathrm{y}}$} & \multicolumn{1}{c}{$\Delta \nu_{\mathrm{N}}$} \\
\hline & & & 2 & $8.87 \mathrm{E}-5$ & $1.61 \mathrm{E}-4$ & $1.84 \mathrm{E}-4$ \\
3 & $7.24 \mathrm{E}-4$ & 4 & $2.25 \mathrm{E}-5$ & $1.19 \mathrm{E}-4$ & $1.21 \mathrm{E}-4$ \\
5 & $1.14 \mathrm{E}-4$ & 6 & $2.15 \mathrm{E}-6$ & $3.55 \mathrm{E}-5$ & $3.56 \mathrm{E}-5$ \\
7 & $1.89 \mathrm{E}-5$ & 8 & $2.55 \mathrm{E}-7$ & $3.16 \mathrm{E}-6$ & $3.16 \mathrm{E}-6$ \\
9 & $2.37 \mathrm{E}-6$ & 10 & $2.48 \mathrm{E}-8$ & $3.94 \mathrm{E}-7$ & $3.95 \mathrm{E}-7$ \\
11 & $2.37 \mathrm{E}-7$ & 12 & $2.03 \mathrm{E}-9$ & $7.39 \mathrm{E}-8$ & $7.40 \mathrm{E}-8$ \\
13 & $1.97 \mathrm{E}-8$ & 14 & $1.43 \mathrm{E}-10$ & $3.29 \mathrm{E}-9$ & $3.29 \mathrm{E}-9$ \\
15 & $1.41 \mathrm{E}-9$ & 16 & $8.87 \mathrm{E}-12$ & $2.35 \mathrm{E}-12$ & $2.35 \mathrm{E}-10$ \\
17 & $8.80 \mathrm{E}-11$ & 18 & $4.89 \mathrm{E}-13$ & $2.75 \mathrm{E}-11$ & $2.75 \mathrm{E}-11$ \\
19 & $4.89 \mathrm{E}-12$ & 20 & $2.43 \mathrm{E}-14$ & $8.15 \mathrm{E}-13$ & $8.16 \mathrm{E}-13$ \\
\hline
\end{tabular}

